\title{
The role of complement in ATTR amyloidosis: a new therapeutic avenue?
}

\author{
Elena Panayiotou*, Eleni Fella, Rebecca Papacharalambous, Stavros Malas, Theodore Kyriakides \\ From First European Congress on Hereditary ATTR amyloidosis \\ Paris, France. 2-3 November 2015
}

\section{Background}

Familial Amyloidotic Polyneuropathy Type I is a lethal autosomal dominant sensorimotor and autonomic neuropathy due to deposition of amyloid fibrils composed of aberrant transthyretin (TTR) protein (ATTR neuropathy). A substitution of valine for methionine at position 30 of the protein is the commonest mutation. ATTRMet30 neuropathy exhibits a great degree of variability, both in the age of onset as well as penetrance among different populations. The penetrance in Cyprus is $28 \%$ compared to $2 \%$ and $80 \%$ in north Sweden and Portugal respectively. Genetic and epigenetic factors have been implicated and although we have previously demonstrated a correlation of complement C1q polymorphisms with age of onset among the Cypriot population, the exact mechanisms remain undetermined. The complement cascade, as a whole, has long been investigated for its association with inflammation and macromolecule aggregate clean-up. In the mouse model of Alzheimer disease, C1q has been shown to modulate beta-amyloid induced complement activation and neuronal loss. C1q has also been shown to be neuroprotective against toxic concentrations of serum amyloid $\mathrm{P}$ and to modulate phagocytosis of soluble pre-amyloid aggregates. Thus $\mathrm{Clq}$ appears to be strong candidate for being a modifier in the phenotype of ATTRMet30 neuropathy.

\section{Methods}

A transgenic mouse model of ATTRMet30 was cross bred with a C1q knockout strain in order to produce a complement deficient ATTRMet30 strain. In addition, the C5a receptor inhibitor PMX53 was administered to the original ATTRMet 30 mouse model. Conventional and real-time PCR were carried out to characterize all mice, Thioflavin S, immunocytochemistry and immunoblotting were utilized to assess amyloid and a number of

Cyprus Insitute of Neurology and Genetics, Non-profit Private Academic, Medical Center, 2370, Nicosia, Cyprus

\section{and take full advantage of:}

- Convenient online submission

- Thorough peer review

- No space constraints or color figure charges

- Immediate publication on acceptance

- Inclusion in PubMed, CAS, Scopus and Google Scholar

- Research which is freely available for redistribution 